\title{
Communicating the Evidence
}

\author{
Mark-Steven Howe \\ Broadway Dental Care, Broadway, Worcestershire, The School of Dentistry, University of Liverpool, Pembroke Place, Liverpool and the \\ Nuffield Department of Primary Care Health Sciences, University of Oxford, Oxford, UK.
}

The 50-50-90 rule: Any time you have a 50-50 chance of getting something right, there's a $90 \%$ probability you'll get it wrong. ${ }^{1}$

Have you thought that after spending considerable effort searching for the best evidence on a specific treatment or diagnosis how much will be lost in translation between yourself and the patient? The words 'guarded' or 'fair' come up a lot in communication with patients, mostly in relation to diagnosis or treatment outcomes, and I would like to explore this observation by asking; What does 'guarded' mean? If we type the word into Google we get 'adjective: guarded - careful not to give too much information or show how you really feel: a guarded response' ${ }^{2}$ I therefore undertook a little study with colleagues and patients in my practice to see how often the word came up, what did the clinicians mean when they used it, and did it match what patients understood. Is there any evidence in the medical/dental research to support my observations? Finally, I would like to discuss how other professions have dealt with these 'words of estimative probability' (WEPS) and are there any lessons to be learned.

\section{The Practice-Based Study}

To see how often dentists use the word 'guarded' I performed a small study with six experienced clinicians writing out hypothetical restorative dental treatment plans without any prompting as to what I was looking for. Eleven clinical cases were presented, and the clinicians were asked to draft out a letter assessing current dental health and future treatment options for each case. The results were collected and produced twenty-six descriptive terms relating to prognosis/risk and outcome. Chart 1. shows a truncated list of the most common WEPS used:

\section{Chart 1. Words of Estimative Probability}

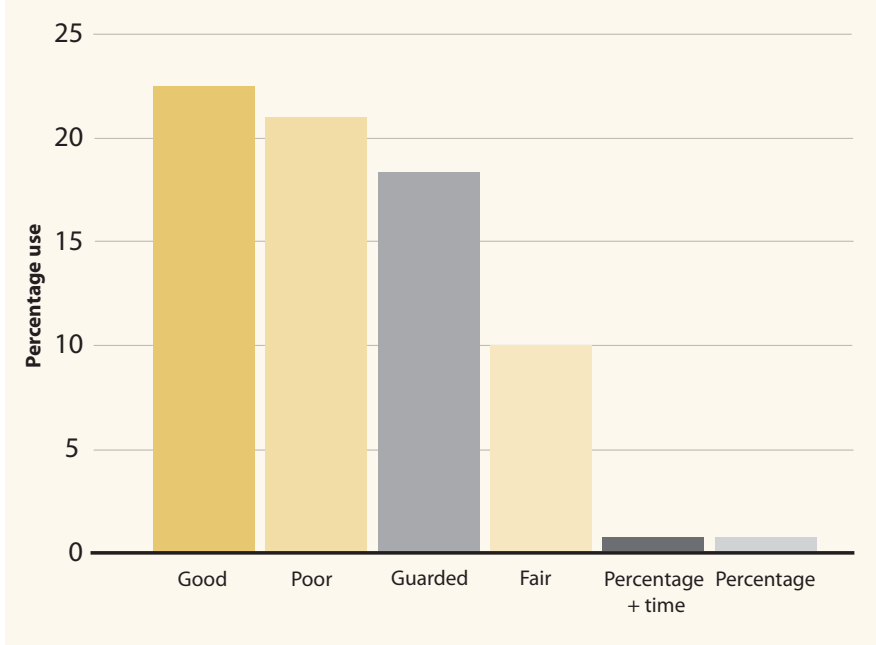

In these results, 'guarded' was the third most common term used (18\%), and in more specific conversations with the same team of clinicians we agreed that the key words (excellent $(95 \%$ $+/-5 \%)$, good $(75 \%+/-15 \%)$, fair $(50 \%+/-10 \%)$, guarded $(25 \%$ $+/-15 \%)$ or poor $(5 \%+/-5 \%))$ related to a quite specific scale of success probabilities.

The next question was; 'What do our patients think some of these WEPS mean?' To find out I did a short randomised questionnaire duplicating some of the methods used by de Bruin ${ }^{3}$ asking sixty consecutive general practice patients what they thought an (excellent, good, fair, guarded or poor) chance of treatment success meant. The results are charted in the box-plot below (Chart 2.):

The chart shows quite clearly that the patients had a higher expectation of a successful outcome than the professionals and in relative terms this disconnect increased almost exponentially as the professional prognosis worsened (Table 1.)

\section{Medical/Dental Evidence}

What can we conclude from these preliminary results and is there any evidence out there to support this observation? I would like to first focus on the tendency of the patients to overestimate benefits of treatment and consequently underestimate harms. There is very little specific literature, but I did find two qualitative dental studies and one medical systematic review that illustrates this bias:

- Hof et al. ${ }^{4}$ found that out of 150 consecutive patients seeking a dental implant, 59\% expected it to last a lifetime and 31\% at least ten years, and 9\% shorter. Patients' estimation of the 10-year implant success rate was $84 \%$.

- A qualitative study 5 on public perceptions of dental implants concluded the participants 'expected dental implants to restore the patients' appearance, functions, and quality of life to absolute normality. They regarded dental implants as a panacea for all cases of missing teeth, overestimated their functions and longevity, and underestimated the expertise needed to carry out the clinical procedures.

- In 2015 a medical systematic review ${ }^{6}$ was undertaken with the objective to 'quantitatively assess patients' expectations of the benefits and/or harms of any treatment, test or screening test'. After reviewing 36 studies, $65 \%$ of patients overestimated a treatment benefit and 50\% underestimated a possible harm from a treatment.

\section{Evidence from other professions}

The Intelligence and National Security community have been working on this precise problem since $1964^{7}$ in an attempt to improve intelligence briefings to non-specialists following the Bay of Pigs disaster in 1961. Sherman Kent proposed that numerical odds were added to the descriptive words to add clarity between 


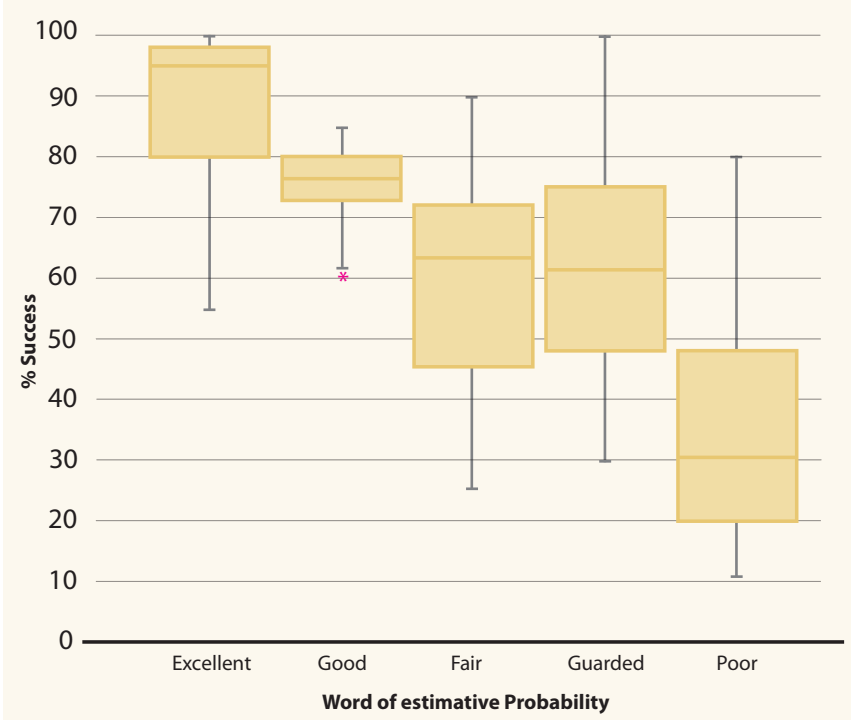

analysts and the decision makers. Even though the logic of his argument was accepted it was never adopted until after the 9/11 terrorist attacks and the Middle Eastern Crisis. The concern was that the numerical probability would be taken as a fact rather than as a probability and the forecaster could be accused of being wrong if the event did not occur. ${ }^{8}$ This concern is what Philip Tetlock in his book 'Superforecasting' calls 'the wrong-side-of-maybe' fallacy, if the weather forecast says there is a $60 \%$ chance of rain and it does not rain the forecaster is judged as being wrong. ${ }^{9}$

All the results show professionals may unconsciously or deliberately use words that can be interpreted elastically; 'guarded' in our case being interpreted by the patients as meaning anything between 30-100 percent success. These elastic words were called Doublespeak in George Orwell's 1984 where the same word represents two contradictory ideas, or Weasel Words ${ }^{10}$ where the word appears to say one thing but in reality, it says the opposite or nothing at all.

\section{Chart 3. Patients guided perception of success}

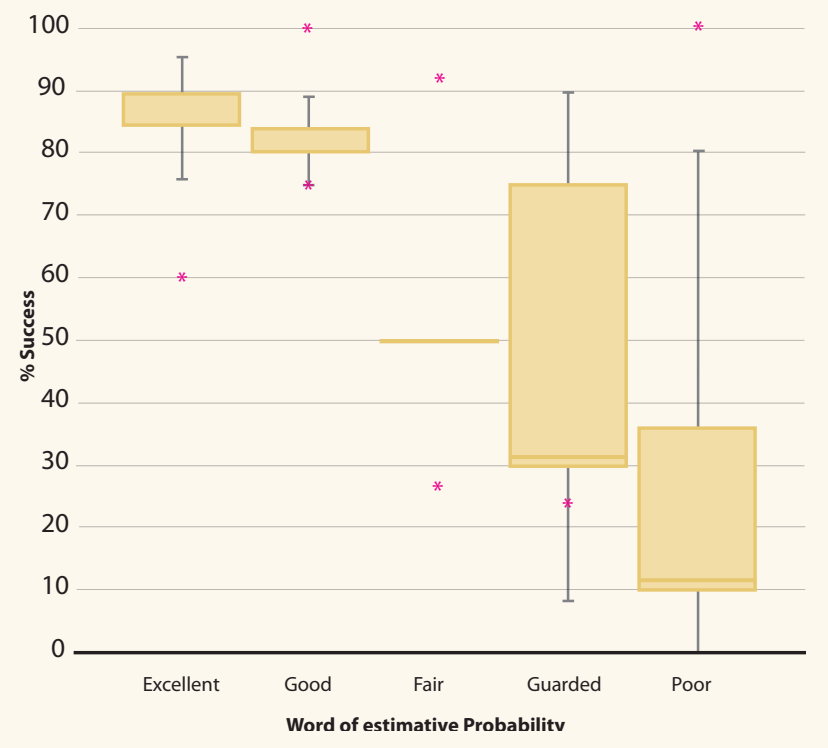

Table 1. Relative difference in patient/professional expectations

\begin{tabular}{l|l|l|l}
\hline & $\begin{array}{l}\text { Median } \\
\text { Professional } \\
\text { Opinion (\%) }\end{array}$ & $\begin{array}{l}\text { Median } \\
\text { Patient } \\
\text { Opinion (\%) }\end{array}$ & $\begin{array}{l}\text { Relative } \\
\text { Difference } \\
\text { (RD) }\end{array}$ \\
\hline Excellent & 95.00 & 94.00 & 0.99 \\
\hline Good & 75.00 & 76.00 & 1.01 \\
\hline Fair & 50.00 & 63.00 & 1.26 \\
\hline Guarded & 25.00 & 62.00 & 2.48 \\
\hline Poor & 5.00 & 30.00 & 6.00
\end{tabular}

\section{What if we add a number and a time frame?}

Taking into consideration the comments Barnes highlighted with intelligence estimates and the concern over precision I modified the presentation of the estimate by firstly adding a five-star/circle $(\otimes \otimes \otimes \otimes \otimes)$ rating scale. This is similar to the infographic used to create online reputation systems that collect, distribute and aggregate feedback about participants for online retailers. ${ }^{11} \mathrm{~A}$ time frame was also added to a survival (time to event) estimate to create a more meaningful prediction, similar to a weather forecast. This type of presentation may not be necessary for simple diagnosis or treatment but becomes more important as cases increase in complexity.

A dental example could be a large periodontally involved five-unit bridge which previously we might describe as having a guarded survival. We could translate this into, 'the five-year survival is guarded $(\otimes \otimes \circ \circ ০)^{\prime}$. We repeated the patient-based randomised questionnaire with new patients using the WEP/ time/infographic and created a new box-plot (Chart 3.) This now showed an improved separation of the categories and the relative differences are now a lot closer to 1.0, but there were still wide interquartile ranges around the words 'guarded' and 'poor'.

\section{Discussion}

Taking the results from my small in-house questionnaire and comparing it with the results from Hoffman's systematic review we can see that optimism bias (individuals see themselves at less risk of an even happening to them than to their peers) is a substantial problem in risk communication with patients. ${ }^{12}$ This deep-seated overestimation of benefits and consequently underestimation of harm combined with inaccurate online information sources 13,14 is likely to become more problematic for patients, especially as treatments increase in complexity and cost, and patients present with multiple co-morbidities.

\section{Conclusion}

Following collecting the best evidence clinicians must try where possible to focus on simple and direct means of communicating treatment benefits and harms to their patients and avoid institutionalised ambiguous language. This will always be confounded by the requirement of our patients needing us to not only 'provide detailed prognoses, they also want their physicians to give them good news and to be optimistic about their illnesses.$^{15}$

1. Rooney A. 50-50-90 Rule. Goodreads. 2007; Available at: https://www.goodreads com/quotes/40186-the-50-50-90-rule-anytime-you-have-a-50-50-chance-of (accessed November 2017).

2. Kirkness A. 2008. Guarded, Cambridge: Cambridge University Press. Available at: 


\section{EDITORIAL}

https://dictionary.cambridge.org/dictionary/english/guarded (accessed November 2017).

3. Bruine De Bruin W, Fischbeck PS, Stiber NA, Fischhoff B. What number is "fifty-fifty"? redistributing excessive $50 \%$ responses in elicited probabilities. Risk Anal 2002; 22: 713-723

4. Hof M, Tepper G, Semo B, Arnhart C, Watzek G, Pommer B. Patients' perspectives on dental implant and bone graft surgery: questionnaire-based interview survey. Clinical Oral Implants Res 2014; 25: 42-45.

5. Wang G, Gao X, Lo EC. Public perceptions of dental implants: a qualitative study. I Dent 2015; 43: 798-805.

6. Hoffmann TC, Del Mar C. Patients' expectations of the benefits and harms of treatments, screening, and tests: a systematic review. JAMA Intern Med 2015; 175: 274-286.

7. Kent S. 1964. Words of Estimative Probability. Available at: https://www.cia.gov/ library/center-for-the-study-of-intelligence/csi-publications/books-and-monographs/ sherman-kent-and-the-board-of-national-estimates-collected-essays/6words.html (accessed November 2017)

8. Barnes A. Making intelligence analysis more intelligent: using numeric probabilities. Intelligence and National Security 2016; 31: pp.327-344.
9. Tetlock PE, Gardner D. Superforcasting: The art and science of prediction. 2015. pp 57-58.

10. Eschholz P, Rosa A, Clark V. Weasel words: The art of saying nothing at all. In Language awareness: Readings for college writers. Macmillan Higher Education; 2013.

11. Resnick P, et al. Reputation systems. Communications of the ACM, 2000; 43: 45-48. Available at: http://dl.acm.org/citation.cfm?id=355112.355122 (accessed Novembe 2017)

12. Weinstein ND. Unrealistic optimism about susceptibility to health problems: conclusions from a community-wide sample. J Behav Med 1987; 10: 481-500.

13. de Barra M. Reporting bias inflates the reputation of medical treatments: A comparison of outcomes in clinical trials and online product reviews. Soc Sci Med 2017; 177: 248-255.

14. Ioannidis JP. Does evidence-based hearsay determine the use of medical treatments? Soc Sci Med 2017; 177: 256-258.

15. Lamont EB, Christakis NA. Prognostic disclosure to patients with cancer near end of life. Ann Intern Med 2001; 134: 1096-1105

Evidence-Based Dentistry (2017) 18, 98 -100. doi:10.1038/sj.ebd.6401265 